\title{
Colonization of Arbuscular mycorrhizal fungi improve salinity tolerance of Eucalyptus (Eucalyptus camaldulensis Dehn.) seedlings
}

\section{Chaiya Klinsukon}

Khon Kaen University Faculty of Science

\section{Saisamorn Lumyong}

Chiang Mai University Faculty of Science

Thomas W. Kuyper

Wageningen University and Research Wageningen Plant Research

Sophon Boonlue ( $\sim$ bsopho@kku.ac.th )

\section{Research article}

Keywords: arbuscular mycorrhizal fungi, salt stress, eucalyptus

Posted Date: February 28th, 2020

DOI: https://doi.org/10.21203/rs.3.rs-15418/v1

License: (c) (i) This work is licensed under a Creative Commons Attribution 4.0 International License.

Read Full License 


\section{Abstract}

Background: Soil salinity is an important problem for agriculture and effecting in the inability to use soil for cultivation. High salt levels reduce plant performance. Arbuscular mycorrhizal fungi (AMF) have been reported to enhance the tolerance of plants under salinity stress. For promote cultivation of economic plant in salt stress area that univariable to use to produce raw material for pulp industry. We determined the effects of AMF on the growth and nutrient status of eucalyptus (Eucalyptus camaldulensis Dehn.) seedlings under salinity stress condition.

Results: Three different clones of Eucalyptus seedlings were pre-inoculated with three salt-tolerant AMF species, namely Glomus sp.2, Gigaspora albida and Gigaspora decipiens or without pre-inoculated. The seedlings were grown in a greenhouse for 45 days. They were then transplanted into individual pots, filled with field soil and subsequently treated with $\mathrm{NaCl}$ solution until the electro-conductivity (EC) reached 10, 15 and $20 \mathrm{dS} \mathrm{m}^{-1}$. They were watered for 90 days under nursery conditions. Increasing salinity levels reduced plant performance, fractional root colonization and the number of spores. Increasing salinity also resulted in a lower $\mathrm{K} / \mathrm{Na}$ ratio. At the same time, performance of the pre-inoculated plants was significantly higher than that of plant that relied on field inoculum only. AMF also significantly increased chlorophyll and leaf proline concentrations and improved the $\mathrm{K} / \mathrm{Na}$ balance.

Conclusion: The results indicate that pre-inoculation with AMF before out planting improves plant performance under salinity stress due to AMF can improve the negative impacts of salinity on the studied physiological, nutrients uptake and biochemical parameters.

\section{Background}

Saline soil and water in 21 st currently are increasing [1]. Increased salinization of arable land may have a large negative global effects, predicted to result in a $30 \%$ loss of land within the next 25 years, and up to $50 \%$ by the middle of the 21 st century [2]. Soil salinity is a serious problem for agriculture and is steadily increasing in many parts of the world, particularly in arid and semi-arid regions [3]. Salinity stress limits crop productivity, growth and plant metabolism. In salt stress conditions, the three main problems for plant growth include water potential (physiological drought), the toxic effect of ions, notable sodium ( $\mathrm{Na}$ ) ions and nutrient imbalance, notably $\mathrm{K}^{+}: \mathrm{Na}^{+}$balance [4].

Arbuscular mycorrhizal fungi (AMF) form symbiotic associations with the roots of many plant species. AMF are found naturally in saline environments [5]. AMF can benefit the host plant by enhancing growth, regulating substances, improving soil properties, and increasing the photosynthetic rate and resistance to plant pathogens and environmental stress [6]. Although AMF fungi alleviate growth reduction caused by salinity stress, the mechanisms involved remain partly unresolved. Studies on salinity stress tolerance in mycorrhizal plants have suggested that AMF plants grow better than non-AMF plants due to increased nutrient uptake and photosynthesis, water use efficiency, the production of osmoregulator, higher $\mathrm{K} / \mathrm{Na}$ ratios and compartmentalization of $\mathrm{Na}$ within certain plant tissues reduction caused by salinity [7]. 
Although AMF can increase host plant tolerance to salinity stress, the capabilities depend on the behavior of each fungal species and strain [8].

Eucalyptus (Eucalyptus camaldulensis Dehn.) or river red gum is a fast-growing plant native to Australia. The species can grow in a wide range of soil properties, from very poor to rich soils. Eucalyptus is one of the most important economic plants in Thailand and is used as a raw material in the production of pulp, oil, furniture and housing [9]. Three Eucalyptus species; E. alba, E. microtheca, and E. camaldulensis have been investigated for their salt tolerance [10]. Eucalyptus camaldulensis Dehn. is a first choice for many growers in Thailand as it can adapt to the saline soil of the northeastern region of Thailand such as in Khon Kaen and Kalasin province. The species is also tolerant to various climate conditions. Cultivation of this species is therefore one option for producing wood in areas with saline soil. An effective way of expanding saline-land usage in Thailand could be to use saline-tolerant strains of AMF for the production of pre-colonized roots of eucalyptus seedlings before planting of cuttings in order to increase the viability of plants after transplanting into saline soil. This study therefore aimed to investigate the potential interaction between saline-tolerant strains of AMF and eucalyptus cultivation under salt stress conditions. We hypothesized that : (1) Increasing salinity levels would reduce plant and mycorrhizal fungal performance; (2) Pre-inoculated plants would be more tolerant to salinity stress than plants that have not been pre-inoculated; (3) Conferral of salt tolerance would be fungal species-specific and eucalypt clone dependent.

\section{Results}

Results of the analysis of variance are provided in Table 1. In almost all cases salinity and mycorrhiza were significant sources of variation. Interactions between AMF and clone were almost always significant sources of variation, indicating species-specific AMF responses on different eucalyptus clones.

Eucalyptus clone and the other interactions were occasionally significant sources of variation as well.

[Insert Table 1 here]

\section{AMF colonization and spore density}

Table 2 shows fractional root colonization and spore abundance of AMF at different salinity levels. Control plants were also colonized, as the field inoculation had not been sterilized, however, colonization levels were much lower than in the pre-inoculated seedlings. Colonization declined with increasing salinity levels. Next to mycorrhiza and salinity as significant sources of variation, variety (clone) was also a significant source of variation. Fractional root colonization on $\mathrm{H} 8$ was higher than that on $\mathrm{H} 4$ and P6. The significant interaction mycorrhiza $\times$ variety was due to the fact that Glomus sp.2 reached highest colonization on P6, whereas G. albida achieved highest colonization on $\mathrm{H} 8$ and $\mathrm{H} 4$. Spore densities were much higher in the pre-inoculated clones that in the clones that did not receive pre-inoculation. Spore densities salinity levels. Variety and the interaction mycorrhiza $\times$ variety were also significant sources of variation (Table 1). Like fractional root colonization spore densities with $\mathrm{H} 4$ and $\mathrm{H} 8$ were highest with $G$. 
albida, while spore densities with P6 were highest with Glomus sp.2. Mycorrhizal colonization and spore abundance were very significantly correlated $(r=0.64 ; n=36 ; P<0.001)$.

[Insert Table 2 here]

\section{Plant performance}

Shoot dry weight was significantly affected by mycorrhiza and salinity. The interaction mycorrhiza $\times$ variety was also a significant source of variation (Table 1). Shoot dry weight was negatively influenced by increasing salinity levels, both for pre-inoculated and control plants. The symptoms of salt toxicity were observed, with leaves becoming sapless and showing signs of chlorosis. The damage to plants was more severe in control plants than in pre-inoculated plants at the same salinity level. At all salinity levels, plant pre-inoculated with $G$. albida usually showed much higher shoot dry weight than plants pre-inoculated with the other AMF or without pre-inoculation. However, at the intermediate salinity levels P6 plants, when pre-inoculated with Glomus sp.2, were significantly heavier than when pre-inoculated with the other AMF or when not pre-inoculated. Under those conditions, plants pre-inoculated with G. albida had lowest shoot dry weight (Table 3). Plant height followed more or less the same pattern as shoot dry weight, with a negative effect of salinity and a positive effect of pre-inoculation by AMF. Plant height of clone $\mathrm{H} 4$ was lower than that of the other two clones. Shoot dry weight and plant height were very significantly positively correlated $(r=0.83 . n=36 ; P<0.001)$.

Leaf relative water content was also significantly affected by salinity, mycorrhiza, variety, and the interaction between mycorrhiza $\times$ variety and salinity $\times$ variety (Table 1 ). Salinity reduced and mycorrhiza increased LRWC. Again, the combination of clone $\mathrm{H} 8$ with G. albida and the combination P6 with Glomus sp.2, resulted in positive interactions. Clone H8 exhibited somewhat lower LRWC than the two other clones (Table 5).

For root dry weight, all three main factors were significant sources as variation. The mycorrhiza $\times$ variety interaction was also a significant source of variation (Table 1). Increasing salinity levels reduced root dry weight. Mycorrhizal plants, especially cutting pre-inoculated with $G$. albida, increased root dry weight. Root dry weight of clone $\mathrm{H} 4$ was significantly higher than that of the other two clones, especially at the two higher salinity levels (Table 3 ). Root dry weight was very significantly correlated with shoot dry weight $(r=0.85, n=36 ; P<0.001)$.

[Insert Table 3 here]

Root length and root surface area were both significantly affected by salinity level, mycorrhiza and the interaction mycorrhiza $\times$ variety. In the case of root surface area, the interaction salinity $\times$ variety was also a significant source of variation (Table 1). Root length had high significantly positive correlation with leaf relative water content (LRWC) but root diameter had significantly negative with root length, specific root length and root tissue density (Table 4). Salinity reduced, and pre-inoculation with mycorrhiza increased 
root length and root surface area. Clone $\mathrm{H} 4$ and $\mathrm{H} 8$ showed the strongest effect in interaction with $\mathrm{G}$. albida, whereas clone P6 showed the strongest interaction with Glomus sp.2 (Table 5)

[Insert Tables 4 \& 5 here]

\section{Plant nutrient concentration}

AMF, salinity and variety of eucalyptus had significantly with all of nutrients concentration in plant tissue. Especially, the interaction of AMF and salinity had high significantly in concentration of $\mathrm{N}, \mathrm{Na}$ and $\mathrm{K} / \mathrm{Na}$ ratio (Table 1). Concentrations of $\mathrm{N}, \mathrm{P}$ and $\mathrm{K}$ in the plant shoots decreased with higher $\mathrm{NaCl}$ concentrations, whereas $\mathrm{Na}$ increased with higher $\mathrm{NaCl}$ concentrations (Table 6). In this study, AMF inoculation was found to enhance nutrient uptake more than the non-AMF plants across all salinity levels. Eucalyptus $\mathrm{H} 4$ and $\mathrm{H} 8$ strains inoculated with Gi. albida had significantly higher total $\mathrm{N}, \mathrm{K}$, and lower $\mathrm{Na}$ absorption than the control. In the case of $\mathrm{P}$, the results reveal that $\mathrm{H} 4$ and $\mathrm{H} 8$ had significantly higher concentrations than the control as a result of the fungus at all salinity levels, with the exception of $\mathrm{P}$ at $20 \mathrm{dS} \mathrm{m}^{-1}$. The eucalyptus P6 strain inoculated with Glomus sp. 2 showed significantly higher N, P and $\mathrm{K}$, and lower $\mathrm{Na}$ absorption than the control (Table 6).

[Insert Table 6 here]

\section{Leaf chlorophyll concentration}

Leaf chlorophyll concentration, an important physiological indicator for plant photosynthetic capacity, was significantly affected by all three main factors (salinity, mycorrhiza, variety) and by all two-way and three-way interactions (Table 1). All of chlorophyll had high significant positive correlation but negative correlation with proline concentration (Table7). Mycorrhiza significantly increased leaf chlorophyll concentration, whereas increasing salinity reduced it. In some combinations of variety and AMF species, there was a major effect of increasing salinity levels from 10-15 dS m-1, whereas in other combinations a major decline was observed only when salinity was increased from 15 to $20 \mathrm{dS} \mathrm{m}^{-1}$. Due to the fact that two-way and three-way interactions were significant, other patterns were difficult to explain. Eucalyptus clones $\mathrm{H} 4$ and $\mathrm{H} 8$ inoculated with G. albida had higher chlorophyll concentration compared to other mycorrhizal treatments, while eucalyptus clone P6 inoculated with Glomus sp.2 had higher leaf chlorophyll concentration (Fig. 1-3) than the other mycorrhizal treatments.

[Insert Table 7 here]

[Insert Figures 1 - 3 here]

\section{Leaf proline concentration}

Like chlorophyll, leaf proline concentrations were significantly affected by all main factors (mycorrhiza, salinity, variety) and all two-way and three-way interactions (Table 1). Proline concentrations increased with increasing salinity and were lower for plants that were pre-inoculated than for control plants, At the 
lowest salinity level there were significant differences between varieties, with $\mathrm{H} 8$ showing lowest proline concentration and $\mathrm{H} 4$ showing highest concentrations. With increasing salinity levels, the differences between the varieties attenuated. Eucalyptus $\mathrm{H} 4$ and $\mathrm{H} 8$ inoculated with $\mathrm{G}$. albida and $\mathrm{P} 6$ inoculated with Glomus sp.2 had significantly lower proline concentrations across all salinity levels (Fig. 4).

[Insert Figure 4 here]

\section{Discussion}

In this research, salinity stress caused by increasing levels of $\mathrm{NaCl}$ significantly reduced plant growth and AMF root colonization, as confirmed by [N Aliasgharzadeh, NS Rastin, $\mathrm{H}$ Towfighi and A Alizadeh [11]] for glycophytes (Allium cepa L., Medicago sativa L., Triticum aestivum L. and Hordeum vulgare L.), A Campanelli, C Ruta, G De Mastro and I Morone-Fortunato [12] for Medicago sativa L. var. icon, and NB Talaat and BT Shawky [13] for Triticum aestivum L. Colonization rates declined with increasing $\mathrm{NaCl}$ levels, indicating that salinity suppressed the growth of AMF [14], inhibited spore germination, inhibited the growth of hyphae after initial infection had occurred [15], and reduced the number of arbuscule [16]. Our results show that increasing levels of salinity resulted in corresponding reductions of plant growth. However, the AMF colonized plants had better results than the non-AMF plant, which agrees with QS Wu and YN Zou [17] for citrus. AAH Abdel Latef and H Chaoxing [18] found that salt stress reduced root, stem and leaf dry matter, but AMF colonization had the effect of improving the dry matter of tomato and increased the growth of Jutropha curcas L. [19]. AMF spores $\mathrm{g}^{-1}$ dry soil was supported by H Evelin, $\mathrm{R}$ Kapoor and B Giri [20] review, who found that many researchers reported that in saline soil where low or zero spores population were found in high soil salinity level. The present study found that AMF spore and root colonization in the non-AMF plants (control) treatment were observed, which was caused by the experiment using non-sterile soil. Natural AMF in soil may therefore grow and infect host plants.

Leaf relative water content (LRWC) decreased with rising levels of soil salinity. In the present study, AMF plant increased LRWC in salinity level when compared with the non-AMF plant (control) which was supported by QS Wu, RX Xia and YN Zou [21], A Campanelli, C Ruta, G De Mastro and I Morone-Fortunato [12], A Kumar, S Sharma and S Mishra [22]. There were a several reasons supported why the AMF plants have a higher LRWC, consisting of: (1) AMF roots had higher hydraulic conductivity at low water potential [23]; (2) AMF induced alterations to the root system [24]; (3) mycorrhizal plants had higher stomatal conductance which increased transpiration[25] ; (4) AMF accumulated solutes and improved plant osmotic adjustment [26]. Meanwhile, RM Auge [27] reported that this may have been the result of an improved water relation by AMF hyphae.

An interaction between the genotype of eucalyptus and the AMF species was found in this study. Plant strains $\mathrm{H} 4$ and $\mathrm{H} 8$ had the highest growth promotion from Gi albida, while the P6 strain had the best growth parameters when inoculated with Glomus sp.2. These findings are supported by the report of AMF's ability to protect plants from the detrimental effects of salt stress may be dependent on the behavior of each species [28], while the plant growth parameters are dependent on the AMF inoculant 
species when examined against the same host species [29].Therefore, arbuscular mycorrhizal colonization was dependent upon different plant species and cultivars [30].

Salinity significantly reduced leaf chlorophyll concentration. Increasing salinity levels causes reduced chlorophyll content [25] due to repression of specific enzymes for the photosynthesis system [31] and reductions of nutrient uptake such as Magnesium $(\mathrm{Mg})$ and Nitrogen $(\mathrm{N})$ for chlorophyll biosynthesis. This is because $\mathrm{NaCl}$ has an antagonistic effect on $\mathrm{N}$ absorption which is essential for the molecular structure of chlorophyll [32]. In this study, all of chlorophyll concentration had positive correlation and AMF plants had significantly higher chlorophyll $a$, chlorophyll $b$ and total chlorophyll than the non-AMF plant in all of salinity level. This suggests that mycorrhizal inoculation could enhance phosphorus $(P)$ and magnesium $(\mathrm{Mg})$ to reduce sodium concentrations in plant, resulting in increased chlorophyll content and overall capability [33]. The accumulation of free amino acid, proline reported modifications induced by water and salt stress [34] and an exogenous application of proline could play an important role in enhancing plant stress tolerance [3]. In saline conditions, numerous plants accumulate proline as a protective osmolyte to maintain an osmotic balance under low water potentials [35]. This study found significantly higher proline concentrations with increased salinity levels. However, proline concentrations were significantly lower in the AMF plant compared to the control. Proline accumulation in plants may be responsive in less salt-tolerance species or to salinity and not necessarily to AMF, because many authors have reported that proline concentration increased in AMF plants compared to non-AMF plants [36]. Conversely, other authors have reported greater proline accumulations in non-AMF plants than AMF plants for example, in Ocimum basilicum L. [37] and Arachis hypogaea L. [38]. From the results, AMF could enhance eucalyptus nutrients uptake; high concentrations of nitrogen $(N)$, Phosphorus $(P)$ and Potassium $(\mathrm{K})$ and low concentrations of Sodium $(\mathrm{Na})$ were found in $\mathrm{Gi}$. albida with eucalyptus strains $\mathrm{H} 4$ and $\mathrm{H} 8$, and in Glomus sp.2 with eucalyptus strain P6. Although salinity stress decreased nutrient uptake, many studies have reported increasing salinity levels lowered $\mathrm{N}$ and $\mathrm{K}$ concentrations, for example in pepper, olive, peanut and chili [39-42]. High concentrations of $K$ can be helpful to maintain $\mathrm{K} / \mathrm{Na}$ ratio, cell osmotic potential from plays control of water relation and effects to increase photosynthetic rate. The results from this study showed that salt tolerance of AMF plant having highest of $\mathrm{K}$ shoot concentration, similar the report which explain that enhancing $\mathrm{K}$ uptake by inoculated AMF plants under salinity stress [43]. AMF interaction with eucalyptus that resulted in an increased growth response was observed, which may be from the specific mechanism and different characteristics such as hyphae distribution, the length of external mycelium and/or nutrient translocation, which supported by report that the relationship between the length of root that had been colonized and the ability to alleviate nutrient limitations caused by soil salinity [44] .

\section{Conclusion}

Salinity altered the growth of Eucalyptus camaldulensis Dehn. due to effects on the physiological and some biochemical parameters. Salinity reduced the uptake of important mineral elements and nutrients. From the study, AMF can improve the negative impacts of salinity on the studied physiological and biochemical parameters. AMF alleviated salt stress by preventing the uptake of $\mathrm{Na}$ and enhancing uptake 
of major plant nutrients, causing the AMF plants to have better growth in saline soil. Thus, the use of AMF provides a sustainable and environmentally safe treatment to improve the salinity tolerance of plants. Future field trials in areas with saline soils are required as the next step.

\section{Methods}

\section{AMF inoculum and plant preparation}

Three AMF species, which are most frequent in saline soil areas in Khon Kaen province, viz., Glomus sp.2 (KKU-BH-001), Gigaspora albida (KKU-BP-001) and Gigaspora decipiens (KKU-BP-002), were isolated from the rhizosphere of eucalyptus from planting sites on saline soil in Ban Phai $\left(6.92 \mathrm{dS} \mathrm{m}^{-1}\right)$, Ban Haeat $\left(5.35 \mathrm{dS} \mathrm{m}^{-1}\right)$. These AMF strains were selected after screening their soil salinity tolerance by growing them in soils supplemented with a solution $(\mathrm{NaCl})$ at a maximum salinity of $20 \mathrm{dS} \mathrm{m}^{-1}$, which is considered very strongly saline [45], using the technique described by CM Hepper [46] with minor modifications. The AMF species were propagated in maize (Zea mays L.) that has short life and a lot of root system by the pot culture technique in a sterilized sandy loam, and then placed in a greenhouse under natural lighting conditions for three months. Colonized root fragments (fractional root colonization $70-90 \%$ ) and spores (24 spores $\mathrm{g}^{-1}$ dry soil) were used as inoculum. Forty-five day old eucalyptus cuttings from three different salt tolerance clones containing commercial clone $\mathrm{H} 4$ can growth in sand, P6 which can growth in loam and non-commercial clone $\mathrm{H} 8$ which can growth in sandy loam which developed and cutting by using the patent of SCG packaging public company limited, Phoenix Pulp \& Paper Public Co. Ltd. and Siam Forestry Co., Ltd, Thailand. All of cuttings were grown in sterilized coconut dust were inoculated with $40 \mathrm{~g}$ inoculum for mycorrhizal treatment, and $40 \mathrm{~g}$ sterilized inoculum as a non-mycorrhizal treatment.

\section{Experimental design}

The eucalyptus cuttings were transplanted into individual pots that filled with field soils, pH 4.87, EC 5.72 dS $\mathrm{m}^{-1}, 0.350 \%$ of organic matter, total $\mathrm{N} 195.30 \mathrm{ppm}$, total $\mathrm{P} 50.05 \mathrm{ppm}$ and total $5,948.98 \mathrm{mg} \mathrm{kg}^{-1}$, exchangeable $\mathrm{Ca} 100 \mathrm{mg} \mathrm{kg}^{-1}$ and $\mathrm{Na} 464.26 \mathrm{mg} \mathrm{kg}^{-1}$. The experiment was a $3 \times 3 \times 4$ complete factorial in a randomized complete block design (RCBD) with three salinity levels $\left(10,15\right.$ and $\left.20 \mathrm{dS} \mathrm{m}^{-1}\right)$, three eucalyptus clones (H4, H8 and P6) and four AMF treatments (Glomus sp.2 KKU-BH-001, Gigaspora albida KKU-BP-001, Gigaspora decipiens KKU-BP-002 and a treatment without pre-inoculation). Each treatment had three replicates. After fourteen days, $5 \%$ of $\mathrm{NaCl}$ solution was added to the soil every seven days to increase the initial EC from $0.24(0 \% \mathrm{NaCl})$ to 10,15 and $20 \mathrm{dS} \mathrm{m}^{-1}$, respectively. All Eucalyptus cuttings were watered with $1,000 \mathrm{~mL}$ every three days. Assessment of plant and fungal performance parameters was conducted at 90 days.

\section{Plant growth measurement and biochemical analysis}


The plant fresh and dry weight (g), plant height $(\mathrm{cm})$, and plant symptoms were measured. The Eucalyptus roots were scanned by an Epson scanner V700 PHOTO and analyzed by WINRHIZO Pro2004a (REGENT Instruments Inc., Qc, Canada). Root colonization was calculated from roots stained with trypan blue [47] according to the method described by A Trouvelot, JL Kough and V Gianinazzi-Pearson [48]. Spore abundance (number of spores $\mathrm{g}^{-1}$ dry soil) was observed after sucrose centrifugation [49]. Plant $\mathrm{N}$ concentration was determined by the Kjeldahl method [50], while P and K concentrations were determined by the wet oxidation method [51] and Na concentration were determined by BS Martinez, AP de Oliveira, FGG Pedro, JC de Oliveira and RD Villa [52] .

\section{Leaf relative water content (LRWC)}

Leaf samples from the top of the plants at the end of the 90 days were used to determine the tolerance of the mycorrhizal and non-mycorrhizal plants at each salinity level, according to . We calculated LRWC using the following equation [53]:

LRWC $(\%)=(F W-D W / T W-D W) \times 100$

Where FW is leaf fresh weight, DW is leaf dry weight after $24 \mathrm{~h}$ of drying at $70{ }^{\circ} \mathrm{C}$, and TW is leaf turgid weight after being soaked in distilled water for $24 \mathrm{~h}$.

\section{Leaf chlorophyll concentration}

Leaf chlorophyll concentration (chlorophyll a, chlorophyll b, and total chlorophyll) was determined by the method described by DI Arnon [54]. $0.5 \mathrm{~g}$ of fresh leaf was ground with $20 \mathrm{~mL}$ of $80 \%$ acetone. The homogenate was then centrifuged at 4,000 rpm for $15 \mathrm{~min}$. The supernatant was read using a spectrophotometer (Thermo Scientific GENESYS 10S UV/Vis Spectrophotometer, model EW-02654-22) at 645 (Chlorophyll a) and $663 \mathrm{~nm}$ (Chlorophyll b). The chlorophyll content was calculated using the following formulae:

Chlorophyll a $(\mathrm{mg} / \mathrm{L})=(12.7 \times$ OD663 $)-(2.69 \times$ OD645 $)$

Chlorophyll b $(\mathrm{mg} / \mathrm{L})=(22.9 \times$ OD645) $-(4.68 \times$ OD663 $)$

Total chlorophyll $(\mathrm{mg} / \mathrm{L})=(8.02 \times$ OD663 $)+(20.2 \times$ OD 645 $)$

Chlorophyll concentrations are given in $\mathrm{mg} \mathrm{g}^{-1}$ fresh leaf weight.

\section{Proline concentration}

Proline determination was performed according to the method described by LS Bates, RP Waldren and ID Teare [55]. $0.5 \mathrm{~g}$ of fresh leaf material was homogenized in $10 \mathrm{~mL}$ of $3 \%$ sulfosalicylic acid and then sieved through Whatman's No. 1 filter paper. Then $2 \mathrm{~mL}$ filtrate solution were mixed with $2 \mathrm{~mL}$ of acidninhydrin and glacial acetic acid in a test tube, respectively. The test tubes were placed in a water bath at $100{ }^{\circ} \mathrm{C}$ for $1 \mathrm{~h}$ and then placed in ice to stop the reaction. The mixture was extracted by $4 \mathrm{~mL}$ toluene and 
the chromophore containing the toluene was separated to measure absorbance of $520 \mathrm{~nm}$ using a Thermo Scientific GENESYS 10S UV/Vis Spectrophotometer (model EW-02654-22). The calculated proline concentration was then compared with the proline standard.

\section{Statistical analysis}

The treatment effects were tested by three-way analysis of variance (ANOVA) using the Statistix program version 8.0. All data complied with the ANOVA assumptions of homoscedasticity and normality. Means were compared between treatments using the Tukey's Honestly Significant Difference (HSD) at a 0.05 probability level

\section{Abbreviations}

AMF:arbuscular mycorrhizal fungi; EC:electro-conductivity; S:salinity; V:variety; SFW:shoot fresh weight; SDW:shoot dry weight; RFW:root fresh weight; RDW:root dry weight; PH:plant height; RL:root length; RS:root surface; LRWC:leaf relative water content; RC:AMF root colonization; TS:total spore; Chl. a:chlorophyll a; Chl. b:chlorophyll b; T Chl..total chlorophyll; N:nitrogen; P:phosphorus; K:potassium; Mg:magnesium; NaCl:sodium chloride; HSD:honestly significant difference; C:control; ns:nonsignificantly; FW:fresh weight; DW:dry weight; TW:leaf turgid weight

\section{Declarations}

\section{Acknowledgements}

We are also indebted to department of Microbiology, faculty of Science, Khon Kaen University, The Center of Excellence on Biodiversity (BDC), Office of Higher Education Commission (BDC-PG2-159011), The Center of Excellence in Microbial Biodiversity and Sustainable Utilization, Faculty of Science, Chiang Mai University, Thailand and Academy of Science, The Royal Society of Thailand. Finally, we also thanks SCG packaging-The Siam Forestry Co.,Ltd. for contribution and providing facilities and eucalyptus seedlings

\section{Authors' contributions}

C.K. and S.B. designed, conducted the experiments, interpreted data and wrote the manuscript. T.W.K. and S.L. revised manuscript. All of authors read and approved the final manuscript.

\section{Funding}

This work was financially supported by Research and Researcher for Industry (RRI) of Thailand, Grant No. PHD58I0033.

\section{Ethics approval and consent to participate}

Not applicable. 
Not applicable

\section{Availability of data and materials}

Not applicable

\section{Competing interests}

The authors declare that they have no competing interests.

\section{Author details}

${ }^{1,4}$ Department of Microbiology, Faculty of Science, Khon Kaen University, Khon Kaen, 40002, Thailand

${ }^{2}$ Department of Biology, Faculty of Science, Chiang Mai University, Chiang Mai, 50200, Thailand

${ }^{3}$ Soil Biology Group, Wageningen University \& Research, P.O. Box 47, 6700 AA Wageningen, The Netherlands

\section{References}

1. Shrivastava P, Kumar R: Soil salinity: A serious environmental issue and plant growth promoting bacteria as one of the tools for its alleviation. Saudi J Biol Sci 2015, 22(2):123-131.

2. Wang W, Vinocur B, Altman A: Plant responses to drought, salinity and extreme temperatures: towards genetic engineering for stress tolerance. Planta 2003, 218(1):1-14.

3. Ashraf M, Foolad MR: Roles of glycine betaine and proline in improving plant abiotic stress resistance. Environ Exp Bot 2007, 59(2):206-216.

4. Marschner H: Mineral Nutrition of Higher Plants; 1995.

5. Juniper S, Abbott LK: Soil salinity delays germination and limits growth of hyphae from propagules of arbuscular mycorrhizal fungi. Mycorrhiza 2006, 16(5):371-379.

6. Al-Karaki GN: Nursery inoculation of tomato with arbuscular mycorrhizal fungi and subsequent performance under irrigation with saline water. Sci Hortic-Amsterdam 2006, 109(1):1-7.

7. Auge RM, Toler HD, Saxton AM: Arbuscular mycorrhizal symbiosis and osmotic adjustment in response to $\mathrm{NaCl}$ stress: a meta-analysis. Front Plant Sci 2014, 5:562.

8. Yang SJ, Zhang ZL, Xue YX, Zhang ZF, Shi SY: Arbuscular mycorrhizal fungi increase salt tolerance of apple seedlings. Bot Stud 2014, 55(1):70.

9. White MKK: Reports Submitted to the Regional Expert Consultation on Eucalyptus - Volume II. In: Eucalyptus Plantations in Thailand Edited by Pousajja R. Bangkok, Thailand; 1996.

10. Fathi R, Prat D: Effects of saline stress on Eucalyptus seedlings. http://dxdoiorg/101051/forest:198905851989, 46. 
11. Aliasgharzadeh N, Rastin NS, Towfighi H, Alizadeh A: Occurrence of arbuscular mycorrhizal fungi in saline soils of the Tabriz Plain of Iran in relation to some physical and chemical properties of soil. Mycorrhiza 2001, 11(3):119-122.

12. Campanelli A, Ruta C, De Mastro G, Morone-Fortunato I: The role of arbuscular mycorrhizal fungi in alleviating salt stress in Medicago sativa L. var. icon. Symbiosis 2013, 59(2):65-76.

13. Talaat NB, Shawky BT: Protective effects of arbuscular mycorrhizal fungi on wheat (Triticum aestivum L.) plants exposed to salinity. Environ Exp Bot 2014, 98:20-31.

14. Latef AAHA, He CX: Effect of arbuscular mycorrhizal fungi on growth, mineral nutrition, antioxidant enzymes activity and fruit yield of tomato grown under salinity stress. Sci Hortic-Amsterdam 2011, 127(3):228-233.

15. McMillen BG, Juniper S, Abbott LKSSaPN, Faculty of Agriculture, The University of Western Australia, Nedlands, WA 6907 (Australia)): Inhibition of hyphal growth of a vesicular-arbuscular mycorrhizal fungus in soil containing sodium chloride limits the spread of infection from spores. 1998, v. 30.

16. Pfeiffer CM, Bloss HE: Growth and Nutrition of Guayule (Parthenium argentatum) in a Saline Soil as Influenced by Vesicular-Arbuscular Mycorrhiza and Phosphorus Fertilization. The New Phytologist 1988, 108(3):315-321.

17. Wu QS, Zou YN: Arbuscular mycorrhizal symbiosis improves growth and root nutrient status of citrus subjected to salt stress. Scienceasia 2009, 35(4):388-391.

18. Abdel Latef $\mathrm{AAH}$, Chaoxing $\mathrm{H}$ : Effect of arbuscular mycorrhizal fungi on growth, mineral nutrition, antioxidant enzymes activity and fruit yield of tomato grown under salinity stress. 2011, v. 127.

19. Kumar A, Sharma S, Mishra S: Influence of Arbuscular Mycorrhizal (AM) Fungi and Salinity on Seedling Growth, Solute Accumulation, and Mycorrhizal Dependency of Jatropha curcas L. Journal of Plant Growth Regulation 2010, 29(3):297-306.

20. Evelin H, Kapoor R, Giri B: Arbuscular mycorrhizal fungi in alleviation of salt stress: a review. Ann Bot 2009, 104(7):1263-1280.

21. Wu QS, Xia RX, Zou YN: Improved soil structure and citrus growth after inoculation with three arbuscular mycorrhizal fungi under drought stress. Eur J Soil Biol 2008, 44(1):122-128.

22. Kumar A, Sharma S, Mishra S: Influence of Arbuscular Mycorrhizal (AM) Fungi and Salinity on Seedling Growth, Solute Accumulation, and Mycorrhizal Dependency of Jatropha curcas L. Journal of Plant Growth Regulation 2010, 29(3):297-306.

23. Kapoor R, Sharma D, Bhatnagar AK: Arbuscular mycorrhizae in micropropagation systems and their potential applications. Sci Hortic-Amsterdam 2008, 116(3):227-239.

24. Kothari SK, Marschner H, George EloPN, Hohenheim University, 7000 Stuttgart 70 (Germany)): Effect of VA mycorrhizal fungi and rhizosphere microorganisms on root and shoot morphology, growth and water relations in maize. 1990, v. 116.

25. Sheng $M$, Tang $M$, Chen $H$, Yang BW, Zhang FF, Huang YH: Influence of arbuscular mycorrhizae on photosynthesis and water status of maize plants under salt stress. Mycorrhiza 2008, 18(6-7):287296. 
26. Abdel Latef AAH: Does Inoculation with Glomus mosseae Improve Salt Tolerance in Pepper Plants? Journal of plant growth regulation 2014, v. 33(no. 3):pp. 644-653-2014 v.2033 no.2013.

27. Auge RM: Water relations, drought and vesicular-arbuscular mycorrhizal symbiosis. Mycorrhiza 2001, 11(1):3-42.

28. Evelin H, Kapoor R, Giri B: Arbuscular mycorrhizal fungi in alleviation of salt stress: a review. Ann BotLondon 2009, 104(7):1263-1280.

29. Van Der Heijden MGA, Klironomos JN, Ursic M, Moutoglis P, Streitwolf-Engel R, Boller T, Wiemken A, Sanders IR: Mycorrhizal fungal diversity determines plant biodiversity, ecosystem variability and productivity. Nature 1998, 396(6706):69-72.

30. Tawaraya K: Arbuscular mycorrhizal dependency of different plant species and cultivars. Soil Sci Plant Nutr 2003, 49(5):655-668.

31. Murkute AAlloT, Delhi (India). Centre for Rural Development and Technology), Sharma SlloT, Delhi (India). Centre for Rural Development and Technology) E-mail:satyawatis@hotmail.com, Singh SKIARI, New Delhi (India). Div. of Fruit and Horticultural Technology): Studies on salt stress tolerance of citrus rootstock genotypes with arbuscular mycorrhizal fungi. 2006, v. 33.

32. Selvakumar G, Thamizhiniyan P: The Effect of the Arbuscular Mycorrhizal (AM) Fungus Glomus intraradiceson the Growth and Yield of Chilli (Capsicum annuum L.) Under Salinity Stress. World Applied Sciences Journal 2011, 14 (8):1209-1214.

33. Giri B, Kapoor R, Mukerji KG: Influence of arbuscular mycorrhizal fungi and salinity on growth, biomass, and mineral nutrition of Acacia auriculiformis. Biol Fert Soils 2003, 38(3):170-175.

34. Ashok A, Nisha K, Karishma K, Neetu N, Anju T, Gupta KK: Arbuscular mycorrhizal symbiosis and alleviation of salinity stress. Journal of Applied and Natural Science 2012, 4(1).

35. Sannazzaro Al, Echeverria M, Alberto EO, Ruiz OA, Menendez AB: Modulation of polyamine balance in Lotus glaber by salinity and arbuscular mycorrhiza. Plant Physiol Bioch 2007, 45(1):39-46.

36. Azooz M, Shaddad MA, Abdel Latef A: The accumulation and compartmentation of proline in relation to salt tolerance of three sorghum cultivars. Indian Journal of Plant Physiology 2004, 9:1-8.

37. Elhindi KM, El-Din AS, Elgorban AM: The impact of arbuscular mycorrhizal fungi in mitigating saltinduced adverse effects in sweet basil (Ocimum basilicum L.). Saudi journal of biological sciences 2017, 24(1):170-179.

38. Al-Khaliel AS: Effect of salinity stress on mycorrhizal association and growth response of peanut infected by Glomus mosseae. Plant Soil Environ 2010, 56(7):318-324.

39. Selvakumar G, Thamizhiniyan P: The Effect of the Arbuscular Mycorrhizal (AM) Fungus Glomus intraradices on the Growth and Yield of Chilli (Capsicum annuum L.) Under Salinity Stress. World App/ Sci J 2011, 14(8).

40. Al-Khaliel AS: Effect of salinity stress on mycorrhizal association and growth response of peanut infected by Glomus mosseae. Plant, Soil and Environment 2010, 56:318-324. 
41. Porras-Soriano A, Soriano-Martín ML, Porras-Piedra A, Azcón R: Arbuscular mycorrhizal fungi increased growth, nutrient uptake and tolerance to salinity in olive trees under nursery conditions. Journal of Plant Physiology 2009, 166(13):1350-1359.

42. Kaya C, Ashraf M, Sonmez O, Aydemir S, Tuna A, Çullu M: The influence of arbuscular mycorrhizal colonisation on key growth parameters and fruit yield of pepper plants grown at high salinity. Scientia Horticulturae - SCI HORT-AMSTERDAM 2009, 121:1-6.

43. Rabie G, Almadini AM: Role of bioinoculants in development of salt-tolerance of Vicia faba plants under salinity stress. African Journal of Biotechnology 2005, 4:210-222.

44. Jakobsen I, Abbott L, Robson A: External hyphae of vesicular-arbuscular mycorrhizal fungi associated with Trifolium subterraneum L. New Phytologist 2006, 120:371-380.

45. Abrol IP, Yadav, J.S.P., Massoud, F.I. : SALINE SOILS AND THEIR MANAGEMENT. In: Salt-Affected Soils and their Management. 1988.

46. Hepper CM: Germination and growth of Glomus caledonius spores: The effects of inhibitors and nutrients. Soil Biology and Biochemistry 1979, 11(3,1979):269-277.

47. Koske RE, Gemma JN: modified procedure for staining roots to detect VA mycorrhizas. 1989, v. 92.

48. Trouvelot A, Kough JL, Gianinazzi-Pearson V: Mesure du taux de mycorhization VA d'un systeme radiculaire. Recherche de methodes d'estimation ayant une signification fonctionnelle. 1986.

49. Daniels BA, Skipper HD: Methods for the recovery and quantitative estimation of propagules from soil [Vesicular-arbuscular mycorrhizal fungi]. 1982.

50. Sparks DL: Methods of soil analysis. Part 3, Part 3. Madison, Wis.: Soil Science Society of America : American Society of Agronomy; 1996.

51. Hesse PR: A textbook of soil chemical analysis: Chemical Pub. Co.; 1972.

52. Martinez BS, de Oliveira AP, Pedro FGG, de Oliveira JC, Villa RD: Determination of the Sodium Concentration in Brazilian Light and Non-Light Powdered Instant Soups by Flame Photometry. Curr Nutr Food Sci 2015, 11(2):131-135.

53. Schonfeld MA, Johnson RC, Carver BF, Mornhinweg DW: Water Relations in Winter Wheat as Drought Resistance Indicators. Crop Science 1988, 28(3):526-531.

54. Arnon DI: Copper Enzymes in Isolated Chloroplasts. Polyphenoloxidase in Beta Vulgaris. Plant Physiol 1949, 24(1):1-15.

55. Bates LS, Waldren RP, Teare ID: Rapid determination of free proline for water-stress studies. Plant and Soil 1973, 39(1):205-207.

\section{Tables}

Due to technical limitations, all table files are only available for download from the Supplementary Files section.

\section{Figures}




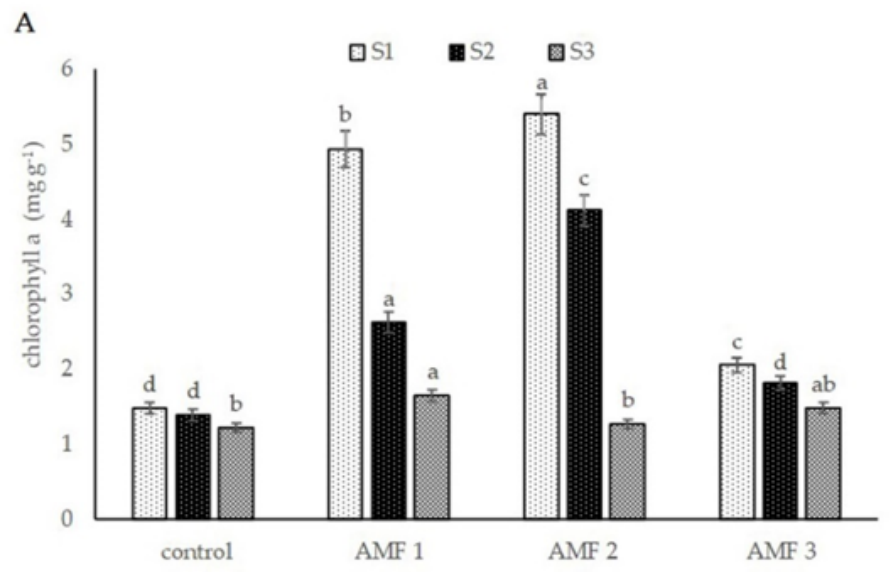

B

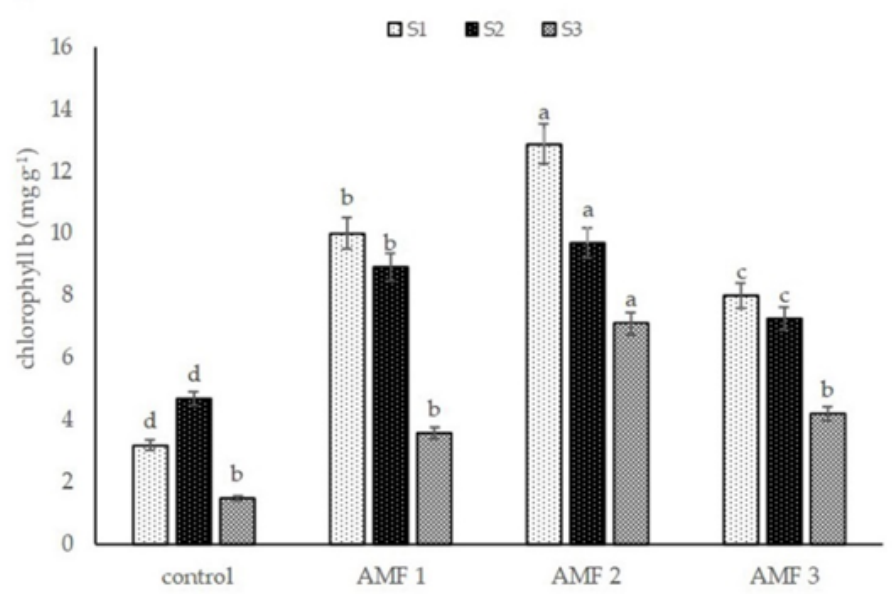

C

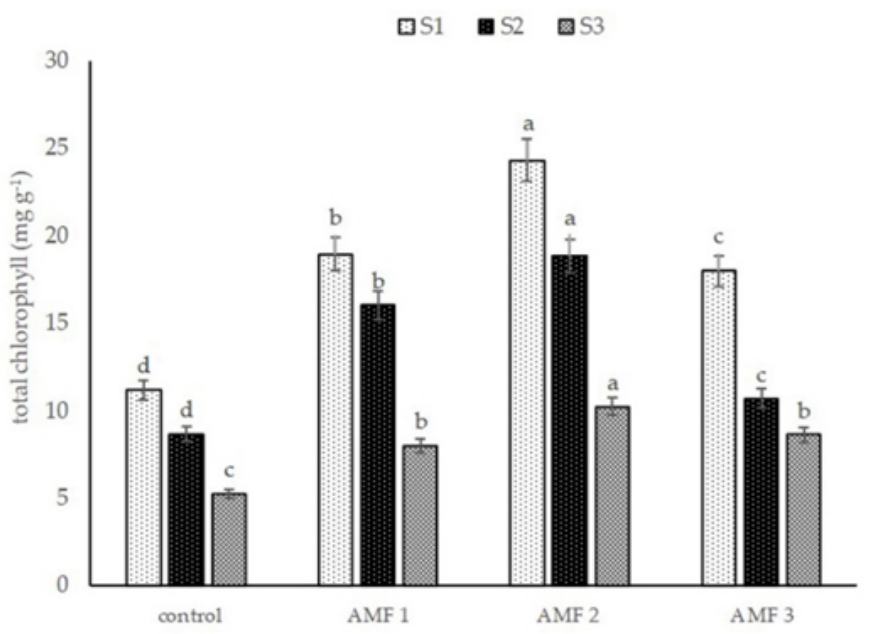

Figure 1

Effect of AMF inoculation and $\mathrm{NaCl}$ stress on leaf chlorophyll, $\mathrm{A}$; chlorophyll $\mathrm{a}, \mathrm{B}$; chlorophyll $\mathrm{b}$ and $\mathrm{C}$; total chlorophyll concentration of eucalyptus $\mathrm{H} 4$ after cultivated for 90 days. Mean values shown, in which the same letters above the bars represent no significant difference, according to HSD at P $\leq 0.05$. Abbreviation: AMF1; Glomus sp.2, AMF2; Gigaspora albida, AMF3; Gigaspora decipean, control; non-AMF inoculation, S1; 10 dS m-1, S2; 15 dS m-1, S3; 20 dS m-1 
A

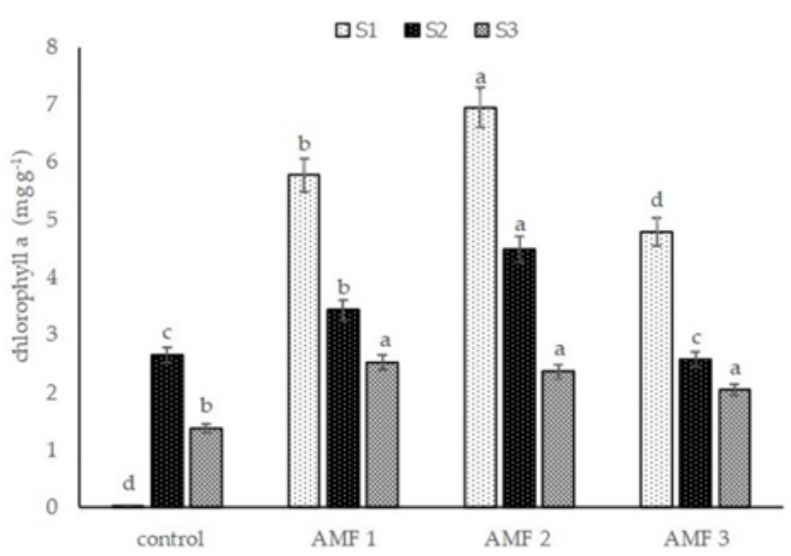

B

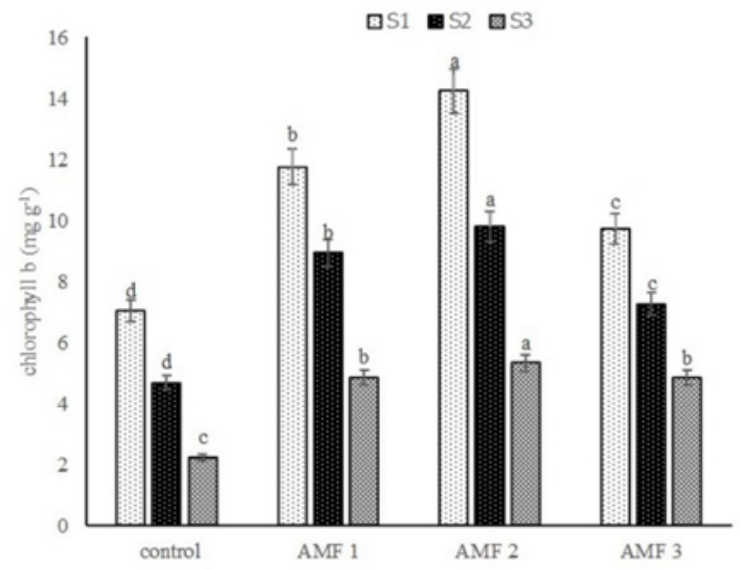

C

口S1 圆 $\mathrm{S} 2 \mathrm{~S} 3$

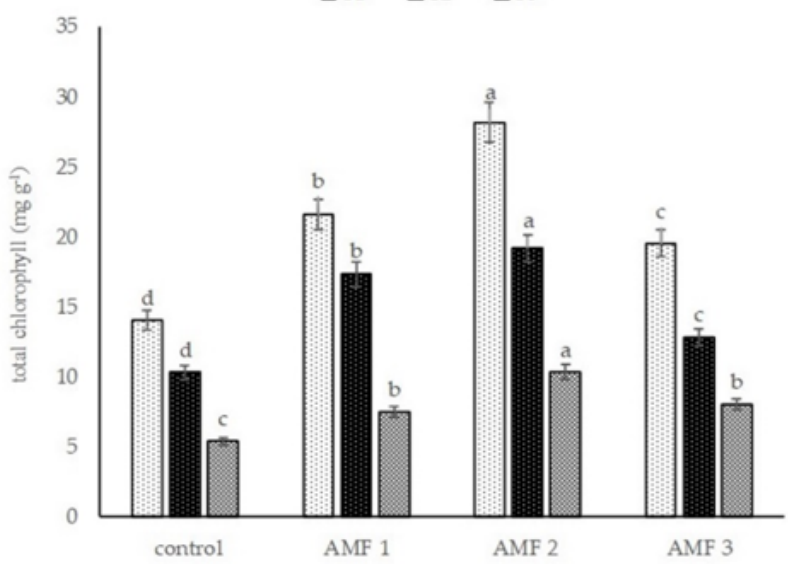

Figure 2

Effect of AMF inoculation and $\mathrm{NaCl}$ stress on leaf chlorophyll $\mathrm{A}$; chlorophyll $\mathrm{a}, \mathrm{B}$; chlorophyll $\mathrm{b}$ and $\mathrm{C}$; total chlorophyll concentration of eucalyptus $\mathrm{H} 8$ after cultivated for 90 days. Mean values shown, in which the same letters above the bars represent no significant difference, according to HSD at $P \leq 0.05$.

Abbreviation: AMF1; Glomus sp.2, AMF2; Gigaspora albida, AMF3; Gigaspora decipean, control; non-AMF inoculation, S1; 10 dS m-1, S2; 15 dS m-1, S3; 20 dS m-1. 


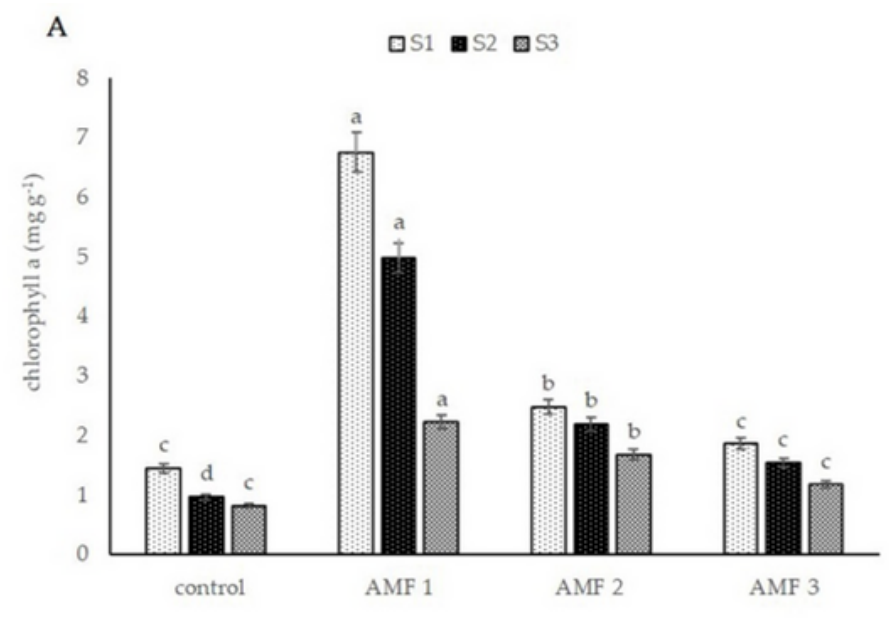

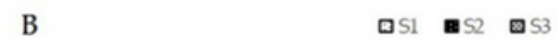
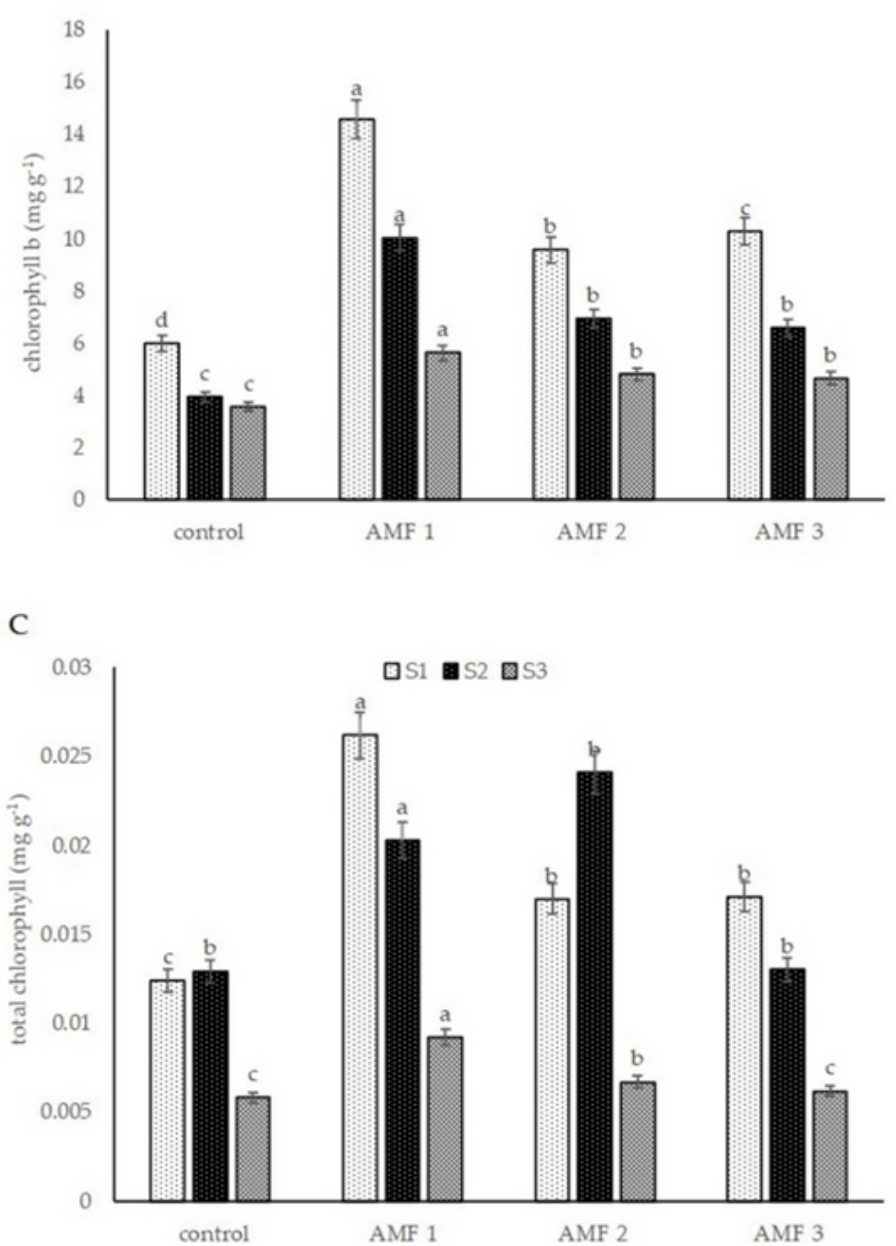

Figure 3

Effect of AMF inoculation and $\mathrm{NaCl}$ stress on leaf chlorophyll $\mathrm{A}$; chlorophyll $\mathrm{a}, \mathrm{B}$; chlorophyll $\mathrm{b}$ and $\mathrm{C}$; total chlorophyll concentration of eucalyptus P6 after cultivated for 90 days. Mean values shown, in which the same letters above the bars represent no significant difference, according to HSD at $P \leq 0.05$.

Abbreviation: AMF1; Glomus sp.2, AMF2; Gigaspora albida, AMF3; Gigaspora decipean, control; non-AMF inoculation, S1; 10 dS m-1, S2; 15 dS m-1, S3; 20 dS m-1. 

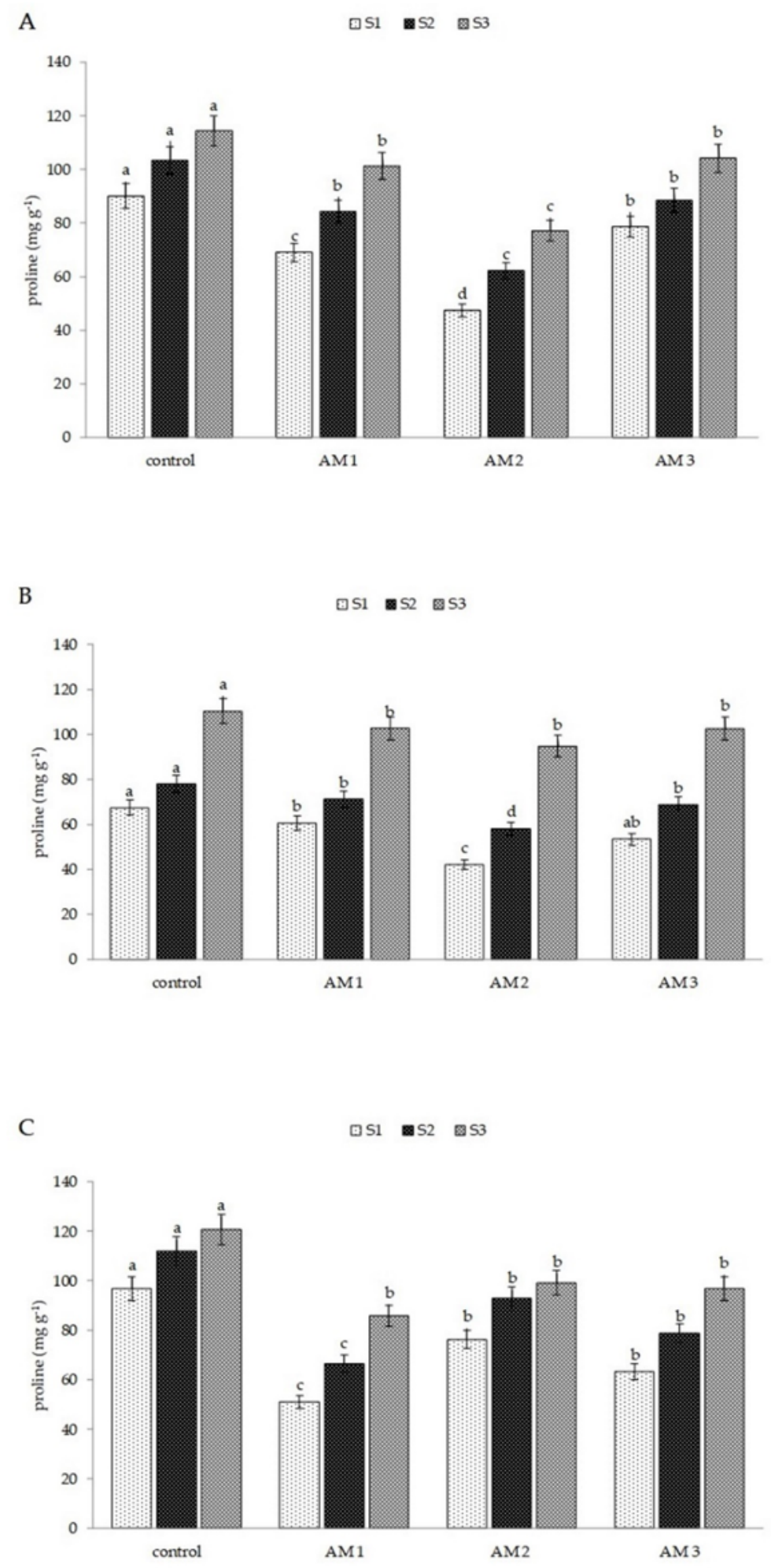

\section{Figure 4}

Effect of salinity level and AMF inoculation on leaf proline concentration of eucalyptus clone H4 (A), H8 (B) and P6 (C) 90 days after planting. Mean values shown, in which the same letters above the bars represent no significant difference, according to HSD at P凶0.05. Abbreviation: AMF1; Glomus sp.2, AMF2; Gigaspora albida, AMF3; Gigaspora decipean, control; non-AMF inoculation, S1; 10 dS m-1, S2; 15 dS m-1, S3; 20 dS m-1. 


\section{Supplementary Files}

This is a list of supplementary files associated with this preprint. Click to download.

- Tables.pdf 